\title{
A TENSION EQUALIZER IN LIFT CARRYING ROPES
}

\author{
Leopold Hrabovský', Peter Michalik²
}

1 VŠB - Technical University of Ostrava, 17. listopadu 15/2172, 70833 Ostrava - Poruba, Czech Republic, e-mail: leopold.hrabovsky@vsb.cz

2 Technical University of Kosice, Faculty of Manufacturing Technologies with seat in Presov, Bayerova 1, 08001, Slovakia, e-mail: peter.michalik@tuke.sk

Received: 2017.10.15

Accepted: 2017.11.01

Published: 2017.12.05

\begin{abstract}
In many high-rise residential buildings or multi-storey warehouses, machinery, so called lifts, are used for the vertical transportation of people or weights between attitudinally distant places. Carriers used for lifts are steel ropes or sprocket chains, on which a cage or a counterbalance is hinged. Apparatus of all carriers, attached to the hinge of the cage or counterbalance, should be even. This can be hundred percently made only by hammer hinge. Fixed or springe hinge cannot be a perfect equalizing apparatus. This article describes an apparatus, which allows an even distribution of the strain into lift carriers, which use springe hinge of carrier ropes.
\end{abstract}

Keywords: tension equalizer, steel rope, contact forces.

\section{INTRODUCTION}

Transported people or weights stand during the transportation on a platform, which is a supporting part of the cabin or in a cage [1]. The cage is carried on fixed ropes, which are attached to the lift shaft. The fixed ropes enable only one movement of the cage and that is a linear movement up and down $[2,3,4]$. The cage is hinged on one or more carriers, which connects it to a kinetic hoisting device, so called elevator machine $[5,6]$.

\section{HINGE OF THE CAGE OR COUNTERBALANCE}

A hinge is such an apparatus, through which the cage or a counterbalance is attached to carriers $[7,8]$. Each carrier must be attached to the hinge separately. The hinges are divided into three categories, according to their construction: fixed, hammer or springe.

Each elevator must be equipped with a hinge switch, which turns off the control circuit and stops the elevator in case of excessive exten- tion, deinitialization or a breakdown of any carrier. Switching off must be forced and the switch must not automatically switch on when the carrier is strained again.

Fixed hinges were formerly used mostly at counterbalances, cages of freight elevators without unaccompanied by persons and small freight elevators, they are currently used at personal elevators and freight elevators in combination with springe hinge at the counterbalance.

Hammer hinges are formed by a lever system, which allows reciprocal turning of the levers and guarantees the even distribution of the overall apparatus on individual carrier. For elevators of bigger dimension, which require a bigger amount of carrier ropes [9], are hammer hinges significantly complex, as it turns out of the stated schemes of hinges.

Complex constructions of hammer hinges and possibilities of conferment of impulse to the action of the trapping device by so called speedometer have led to the use of springe hinges [10], which are much simpler when it comes to construction and have the advantage of a flexible mesh. If the constants are the same for all 
the springs, the same strain of all carrier ropes is guaranteed. The danger of vibration of the cage in the vertical direction is caused by a sharp mesh $[11,12,13]$.

\section{MECHANICAL EQUALIZER OF TENSILE FORCES IN THE ROPES OF THE ELEVATOR}

In the lift shaft of the relevant building, the free end of the carrying rope is mechanically attached to the eye of the suspension bolt with rope clamps. Metric thread made on the suspension bolt, for more details see Figure 2, is laced through the aperture in the clamping console, so called baseplate, 9. On the thread of the suspension bolt, above the level of the upper area of the clamping console, there is a bowl 7 mounted in the stated direction, to which one end of the wound compressive spring 10 is inserted. On the other end of the wound cylindrical spring there is a bowl 7 inserted, suspension bolt is equipped with a backplate 11 and a hexagonal nut 6 on its end. In this way the suspension bolt is detented against extrusion down in the direction of the lift shaft (by the influence of the tensile force in the carrying rope) through the aperture in the clamping console. If the inside diameter of the wound cylindrical spring 10 is significantly bigger than the inside diameter of the suspension bolt 13, these two diameters are centered with the plastic centering insert 19.
The described apparatus [2], see Figure 1, for more details see Figure 2, is made of the screw spindle 1 , which consists of double screw 2 , a simple screw 3 and a nut 4 .

Double screw 2 is equipped with trapezoidal isosceles simple thread and a trapezoidal isosceles simple thread, made on the inside longitudinal aperture, at the outer diameter of the cylindrical area. The simple screw 3 is equipped with trapezoidal isosceles simple thread on the outer cylindrical area. The cylindrical nut 4 is equipped with 2 apertures at the outer area, into which pins are inserted, which are made in the heelpiece of the cylindrical rod 9 and the screw with a cylindrical head with inside hexagon 23. The pin on the end of the cylindrical rod 9 along with the pin on the end and the adjusting screw 23 mutually mechanically connect the cylindrical nut 4 to cylindrical object 18 of the apparatus for the detection of the tensile forces.

The simple screw 3 of the apparatus for the detection of the tensile forces is terminated with the cylindrical part, with the longitudinal aperture in the constructionally chosen distance of the axis of the aperture from the end of the cylindrical part. This cylindrical part of the simple screw 3 is inserted to the aperture of the flange 16. The prevention of the mutual angular rotation of the cylindrical part of the simple screw 3 (of the telescopic spindle 1) and the flange 16 is secured with the screw with the cylindrical head with inside hexagon 22, flexible backplate 21 and hexagonal
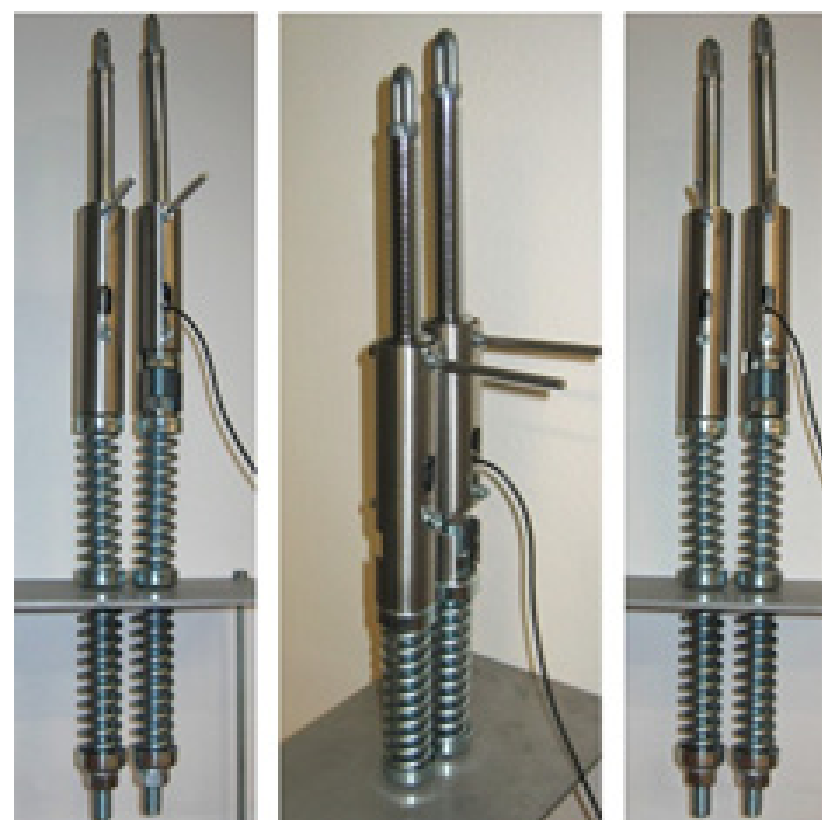

Figure 1. The apparatus for the detection of the tensile forces 


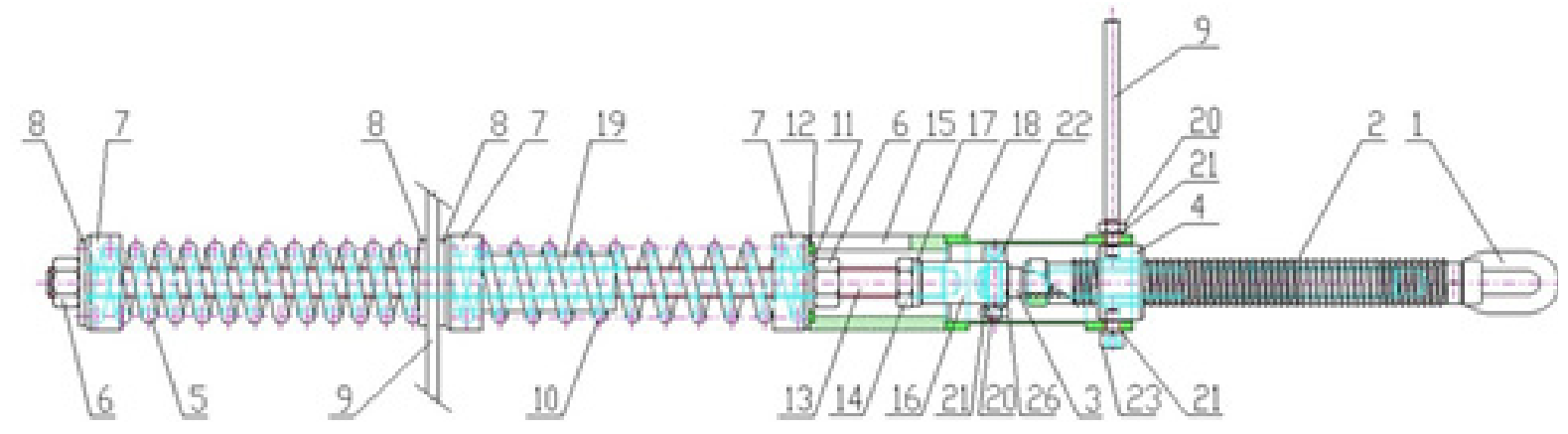

Figure 2. Detail of the engineering design of the apparatus for the detection of the tensile forces [14]

low nut 20. To the aperture with an inside thread on the opposite part of the flange 16, the metric thread of the threaded rod 13 (made on the outer cylindrical area) is screwed.

The outer metric thread of the threaded rod 13 , screwed on the inside metric thread of the hub 16 , is secured against release with the flexible backplate 17 and the hexagonal nut 14 . On the threaded rod 13, there is the hexagonal nut 6 put on it in the relevant distance, which bears over the backplate 11 on the bowl 7. The outer diameter of the backplate 11 centres, towards the inside diameter of the object of the apparatus for the detection of the tensile forces 15 , centering ring 12 .

The wound cylindrical spring 10 is placed in the bowls 7 by its both end cut fronts. The bowl 7 in the lower part (see the left bowl in Figure 2 clutching the spring 10) bears, over the backplate 8 , on the baseplate 9 . One cut front of the wound cylindrical spring bears over the backplate 8 against the opposite side of the area of the baseplate, its second cut front is placed in bowl 7. This bowl 7 is put on the threaded rod 13 and is secured against extrusion with the nut 6 over the backplate 8 .

\section{DESCRIPTION OF THE APPARATUS FOR THE DETECTION OF THE TENSILE FORCES}

In the real practice, the suspension bolt is laced through the clamping console (here the baseplate 9, see the Figure 2), to which eye (realized in the end part of the suspension bolt), one cross section of the carrying rope is attached by the rope clamps.

The suspension bolt is simulated by the threaded rod 13 (of the same diameter as the diameter of the suspension bolt). The tensile force affecting the axis of the suspension bolt (the ten- sile force is in the practice educed from the proportional nominal load, defined by the number of used carrying ropes and the way of used snubbing, in the appropriate branch of the carrying rope from the weight of the lift cabin or counterbalance) is at the described functional sample educed from the same size of the tensile force affecting in the axis of the threaded rod 13 through the force of the compression wound spring 5 in tightened state. The compression wound spring 5 is pushed to the required force (necessary tensile force affecting in the axis of the suspension bolt) through the nut 6 . In the moment of reaching the required axial force in one threaded rod 13 , the tensile force of a different size is educed in the same way in the axis of the second suspension bolt 13 of the apparatus for the detection of the tensile forces, see the Figure 3.

Different outcomes of the tensile forces educed from the different preloading of the wound compression cylindrical springs 5 , are scanned by a foil strain gauges 24 , which are attached to the area of the cylindrical object 18 . For the purpose of reaching the same size of the tension in steel ropes (here according to the Figure 1, in the threaded rodes 13), the double screw 2 of the partial screw spindle 1 is turned in the relevant direction, which causes the compression (release) of the partial wound compression spring 10 . The compression, eventually release (it is caused by the sense of turning the double screw 2 of the partial screw spindle 1), of the partial wound compression spring 10 is caused by the engineering design of the apapratus for scanning and balancing the tensile forces, specifically by the fixed distance between placing the cylindrical nut 4 and the lower area of the object 15.

In the lower part of the object 15 , shoulder is realised, into which the centering ring 12 is inserted. The inside diameter of the centering ring 12 defines the clearance between the outer diameter 

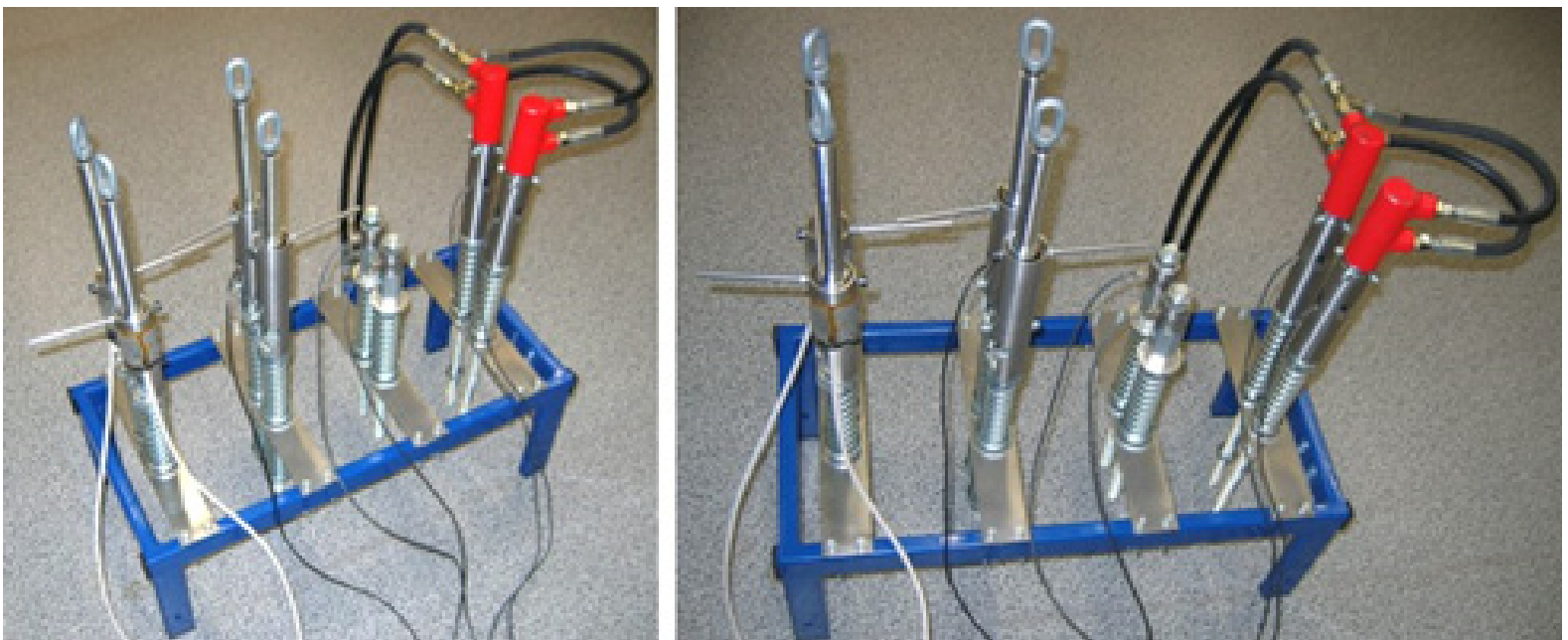

Figure 3. Realization of the apparatus for the detection of the tensile forces

of the backplate 11 and the inside diameter of the shoulder of the object 15 . In the moment of turning the double screw 2 of the partial screw spindle 1 in the stated direction, it comes into extension (shortening) of the mutual distance between the pins, in which the cylindrical nut 4 is placed and the centering ring 12 , which is inserted into the shoulder in the lower part of the object 15 . The centering ring 12 bears on the outer part of the surface of the bowl 7. In the moment of turning the double screw 2 of the partial screw spindle 1 in the stated direction, the bowl 7 is pushed by the centering ring 12 (the distance between the cylindrical nut 4 and the surface of the bowl 7 is being prolonged) and it causes the compression of the wound compression spring 10 (while turning the double screw 2 of the partial screw spindle 1 in the opposite direction, the bowl 7 is being pushed to the centering ring 12 (because the direction between the pins of the cylindrical nut 4 and the surface of the bowl 7 is being shortened) and that causes the release of the wound compression spring 10).

On the threaded rod 13 (in the practice called suspension bolt) above the bowl 7, there is the backplate 11 put on and above it there is the hexagonal nut 6 . By tightening (releasing) the nut 6 , it is possible to fix the tightened (released) spring 10 in the required state.

Regarding the fact that it is possible, by the foil strain gauges 24 , to continuously scan the results of the deformation in the partial cylindrical object 18, which is the part of the apparatus for the detection of the tensile forces, and compare that to the results of the deformation in the other cylindrical object 18 , it is possible to reach the same results by the above stated process (to balance the tensile forces in partial carrying ropes) of the tensile forces educed from the threaded rods from the original different set results educed from the different preloading of the wound compression cylindrical springs 5 .

\section{ACTIVITIES OF THE APPARATUS FOR THE DETECTION OF THE TENSILE FORCES}

The different results of the tensile forces educed from different deforming energy of wound compression cylindrical springs are scanned by resistive biaxial strain gauges, attached to each of the two pieces of the upper part of the equalizer of tension of lift ropes, see Figure 4.

The measured quantity (the pressure force educed by the deformation of the upper part of the tension equalizer of ropes of cable lifts from tensile forces in threaded screw) is scanned by resistive strain gauges. By mutual connection of the strain gauges into Wheatston bridge it comes at a change of load force to an elastic deformation of a deformation part (that is the upper part of the apparatus for the detection of the tensile forces) and consequently to the change of results of the resistances of each strain gauge, so called bridge ballancing. Wheatston bridge is powered from the measuring system by the direct current voltage and consequently the voltage is scanned on the signal side of the bridge. The measured voltage is transferred through $24 \mathrm{bit} \mathrm{A} / \mathrm{D}$ converter in modul BR4 into digital value, which is saved in the data system of the GATE unit. Here the value is calibrated according to the settings of the whole 


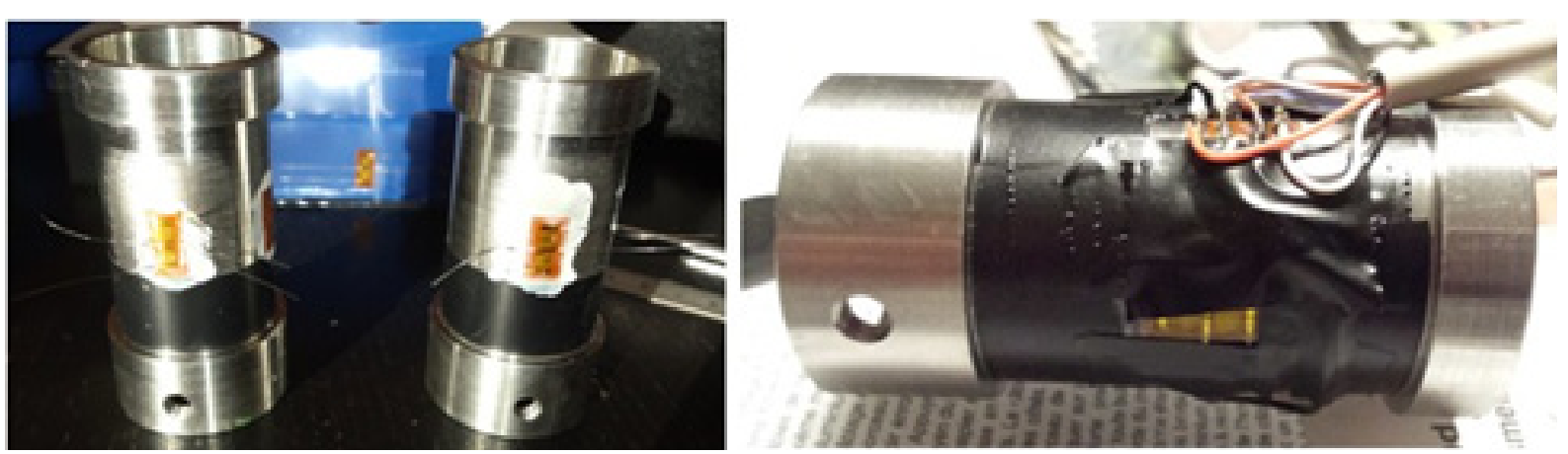

Figure 4. Mobile mechanical tension equalizer

system, the required compensation of dislocation and amplification is added to it by the user. Consequently, the value is sent through Ethernet and connected AP (Access point) through WiFi signal into the measuring computer, where it is saved. The control of the measuring system Dewetron is realised through DEWEsoft software. The gained immediate values of the real sizes of the measured forces; along with the graphic process of changes of those values in the chosen time period and the record of the values; from the undertaken experimental tests (see the Figure 5) during checking the technology of tension equalizers of ropes of the rope lifts enables to conclude that the technology works and meets all the requirements imposed on it.

Different values of tensile forces exerted by different forces in the carrier ropes and thus by pre-tensioning of the cylindrical compression coil springs, see Figure 5, where a tensile force in one rope is visualization blue and tensile force in here- after rope is visualization red. In order to achieve the same value of the tensional force in the carrier ropes, the double screw of the individual screw spindle is rotated, see Figure 2, which leads to a compression (release) of the given compression coil spring. Compression or release (given by the purpose of rotation of the suspension screw of the individual screw spindle) of the individual compression coil spring are due to the design of the movable mechanical tension off-setter, namely the fixed length distance (at a given moment) between the plane of placement of the cylindrical nut (the link is provided by the pins inserted into the openings created in the end sections of the cylindrical rod and screws with cylindrical head and inner hexagon) and the upper surface of the bearing bracket.

In the lower part of the body of the movable mechanical tension off-setter, there is a mounting (neck-down), into which a centering ring is inserted, see Figure 2. The inner diameter of the cen-

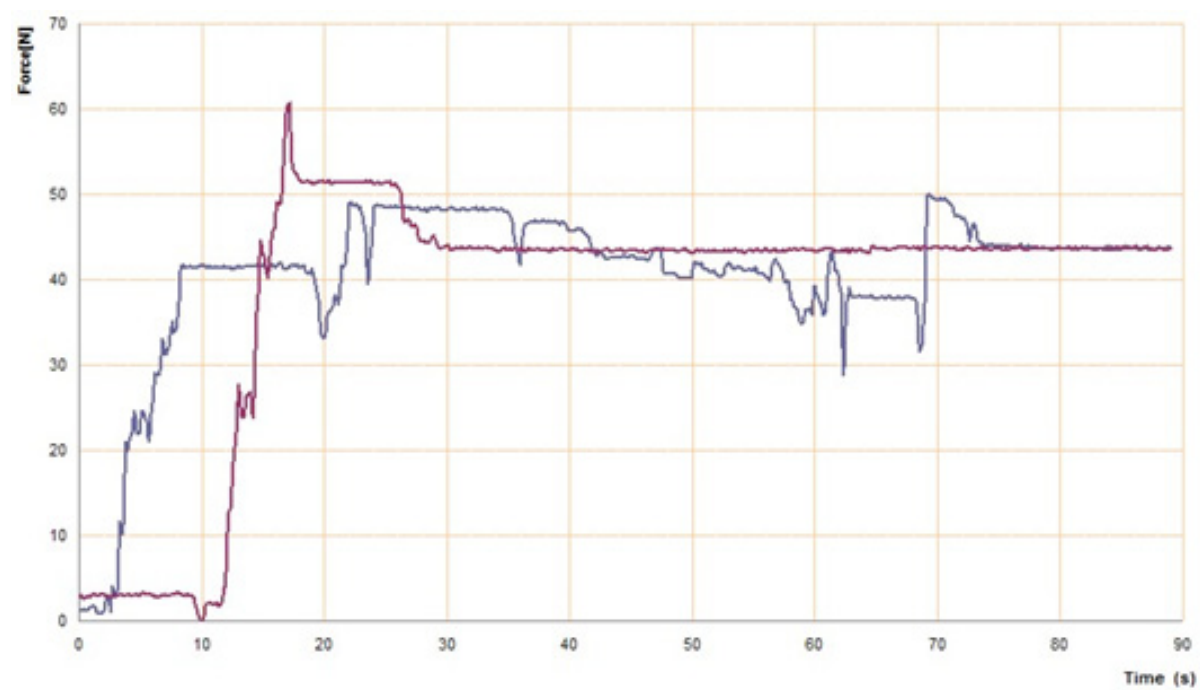

Figure 5. The process of the two tensile forces measured by the DEWEsoft programme in the tension equalizers of ropes and rope lifts 
tering ring thus defines a play between the outer dimensions of the washer and the inner diameter of the body mounting. At the moment of rotation (in a given direction) of the double screw of the individual screw spindle, there is an extension (shortening) of the distance between the plane of placement of the cylindrical nut (in relation to the body) and the upper surface of the bearing bracket. The mutual mechanical connection of the hub with the suspension screw and the screw spindle, which is through the cylindrical nut mechanically interconnected with the body of the movable mechanical tension off-setter, gains one degree of freedom. That means the hub allows a shift in relation to the longitudinal axis of the body.

Based on the assumptions described above, at the moment of rotation (in a given direction) of the double screw of the individual screw spindle, there is an extension (shortening) of the distance between the plane of placement of the cylindrical nut and the centering ring, which is inserted into the mounting in the lower part of the body. The centering ring leans against the outer surface of the bowl. At the moment of rotation of the double screw of the screw spindle in a given direction, the bowl is being pushed away by the centering ring (the distance between the cylindrical nut and the surface of the bowl is extending), thereby causing compression of the coil spring (when rotating the double screw of the screw spindle in the reverse direction, the bowl is being pushed to the centering ring (the distance between the pins of the cylindrical nut and the surface of the bowl is shortening), thereby causing release of the coil spring).

Above the bowl, the washer is threaded on the suspension screw followed the hexagonal nut. By tightening (loosening) the nut, it is possible to fix the compressed (released) spring in the desired state. Since the value of the tensional force in the individual suspension screw, see course of blue curve in Figure 5, can be continuously gauged and compared to the value of the tensional force in the adjoining suspension screw, see course of red curve in Figure 5, using tensional force sensors (in practice in adjoining suspension screws), the above mentioned procedure enables achieving the same values (offsetting the tensional forces in the individual carrier ropes) of the tensional forces exerted in the suspension screws from the initially differently set values caused by the different pre-tensioning of the cylindrical compression coil springs.

\section{CONCLUSIONS}

This article describes an apparatus, which allows an even distribution of the strain into lift carriers, which use springe hinge of carrier ropes.

The possibility to measure the real value of the tensile force in the partial cross section of the carrying lift rope, to compare this to the value of the tensile force of the adjacent carrying rope and consequently, on the basis of the knowledge of the difference of both (or more) values of tensile forces, to equalize both values in mechanical way (by turning the nut attached to the rope hinge or to the rod), it enables to use the described apparatus in practice to set the appropriate rope tension in multi-roped hinges.

The different results of the tensile forces educed from different deforming energy of wound compression cylindrical springs are scanned by resistive biaxial strain gauges, attached to each of the two pieces of the upper part of the equalizer of tension of lift ropes.

The measured quantity (the pressure force educed by the deformation of the upper part of the tension equalizer of ropes of cable lifts from tensile forces in threaded screw) is scanned by resistive strain gauges.

The gained immediate values of the real sizes of the measured forces; along with the graphic process of changes of those values in the chosen time period and the record of the values; from the undertaken experimental tests during checking the technology of tension equalizers of ropes of the rope lifts enables to conclude that the technology works and meets all the requirements imposed on it.

\section{Acknowledgements}

This work is a part of research project TA ČR GAMA TG01010054 and VEGA 1/0619/15.

\section{REFERENCES}

1. Molnar V., Boroska, Jan., Decmanova J.: Mechanical properties of steel rope wires - quality test assurance. Acta Montanistica Slovaca 15, 2010, 23-30.

2. Kmet S., Stanova E., Fedorko G., Fabian M., Brodniansky J.: Experimental investigation and finite element analysis of a four-layered spiral strand bent over a curved support. Engineering Structures 57, 2013, 475-483. 
3. Stanova E., Fedorko G., Kmet S., Molnar V., Fabian M.: Finite element analysis of spiral strands with different shapes subjected to axial loads. Advances in Engineering Software 83, 2015, 45-58.

4. Fedorko G., Stanova E., Molnar V., Husakova N., Kmet S.: Computer modelling and finite element analysis of spiral triangular strands. Advances in Engineering Software 73, 2014 11-21.

5. Ivanco V., Kmet S., Fedorko G.: Finite element simulation of creep of spiral strands. Engineering Structures 117, 2016, 220-238.

6. Debski H., Teter A., Kubiak T., Samborski S.: Local buckling, post-buckling and collapse of thin-walled channel section composite columns subjected to quasi-static compression. Composite Structures, 136, 2016, 593-601.

7. Palencar R., Duris S., Ranostaj J.: Conclusions and some comments on the calculation of uncertainty when constructing a temperature scale. Measurement Techniques, 54(8), 2011, 910-920.

8. Jachowicz T.: Construction of clamping units of injection molding machines. Polimery 2005, 2 (50), 110-117.
9. Dvořák J.: ČSN EN 81-1+A3. Safety rules for the construction and installation of lifts - Part 1:Electric lifts. 2010 - in Czech.

10. Ham S.H., Roh M.I., Lee H.: Simulation of load lifting with equalizers used in shipyards. Automation in Construction 61, 2016, 98-111.

11. Peterka P., Krešák J., Kropuch S., Fedorko G., Molnar V., Vojtko M.: Failure analysis of hoisting steel wire rope. Engineering Failure Analysis 45, 2014, 96-105.

12. Hrabovský L.: Action on crane runway caused by horizontal forces due to crane skewing. Key Engineering Materials 669, 2016, 391-399.

13. Choi Y., Lee H.: A study on the control system for the unintended car movement protection means to meet the international standards of lifts. Journal of Electrical Engineering and Technology 12, 2017, 2079-2087.

14. Hrabovský L.: A tension equalizer in lift carrying ropes. 2017. https://isdv.upv.cz/webapp/webapp. pts.det?xprim $=10163765 \&$ lan $=$ cs\&s_majs $=\&$ s puvo=leopold $\% 20$ hrabovsk\%C3\%BD\&s_ naze $=\&$ s_anot $=$ 